\title{
Mesenchymal Stem Cells Regulate IL8 and TGFA Expression in a Novel Leucocytes Depleted Platelet- Rich Plasma-Skin Equivalent in a Preliminary in vitro Study of Chronic Wound Healing
}

\section{Elisa Seria ( $\nabla$ elisa.seria@um.edu.mt)}

University of Malta Faculty of Medicine and Surgery https://orcid.org/0000-0002-3003-4151

\section{George Galea}

University of Malta

Gabriella Grech

University of Malta Medical School

Sarah Samut Tagliaferro

University of Malta

Alexander Felice

University of Malta

\section{Research}

Keywords: Skin equivalent, Wound healing, Inflammation, Mesenchymal stem cell, Cell therapy

Posted Date: September 15th, 2020

DOI: https://doi.org/10.21203/rs.3.rs-73514/v1

License: (c) (1) This work is licensed under a Creative Commons Attribution 4.0 International License.

Read Full License 


\section{Abstract}

Background: Chronic leg ulcerations are associated with Haemoglobin disorders, Type 2 Diabetes Mellitus, and long-term venous insufficiency. Mesenchymal stem cells (MSCs) ability to modulate the inflammatory response represents the fundamental requisite for their applicability as a treatment of chronic wounds.

Methods: This study aimed to develop a novel bioactive platelet-rich plasma (PRP)-leukocytes-depleted scaffold to reproduce typical clinical wound of patients with poor chronic skin perfusion and low leucocytes infiltration. After scratching the wound model to mimic injury three conditions were compared; an untreated condition, a condition treated with recombinant TNF to mimic an inflammatory state and a condition treated with TNF and also with MSCs to evaluate how the latter's immunomodulatory properties affect the therapeutic outcomes in an inflammatory state. Gene expression of IL 8 and TGFA were analysed in biological triplicates of the three conditions. Statistical analysis was done through a paired student t-test and a $\mathrm{p}<0.05$ was considered significant.

Results: We set up a skin model that consisted of a leukocyte-depleted, platelet-rich plasma scaffold, with embedded fibroblasts as dermal equivalent and seeded keratinocytes on it as multi-layered epidermidis. IL 8 expression increased upon scratching $(p=0.014)$ and continued to increase up to day $1(p=0.048)$. IL8 expression decreased upon administration of TNF $(\mathrm{p}=0.005)$ but then increased again. IL 8 expression decreased in the untreated condition after day 1 as the natural healing process took place and was lower than in treated conditions in day $8(\mathrm{p}=0.048)$. TGFA expression decreased upon scratching $(\mathrm{p}=0.006)$ and increased again in day 1 , more so in the untreated than in the treated conditions $(p=0.02)$. TGFA expression decreased again in day 4 in the study group before increasing sharply $(p=0.027)$ in day 8 to reach pre-scratch levels.

Conclusion: This study found that a leukocyte-depleted PRP-based skin equivalent can be useful in the study of treatments of chronic wounds. This study also indicates that MSCs appear to modulate the expression of $I L 8$ by switching from an immunosuppressive phenotype to a pro-inflammatory phenotype. These results indicate that the administration of MSCs could offer a potential therapeutic approach for the treatment of leg ulcers in patients with poor skin perfusion.

\section{Background}

Leg ulcers are common, and their incidence rises with age, leading to a negative impact on the quality of life and considerable cost for the health service [1]. Haemolytic disorders such as Sickle Cell Disease and $\beta$-thalassaemia are common in Malta and other Mediterranean countries due to a number of $\beta$ globin gene mutations [2]. Haemoglobin disorders are associated with chronic cutaneous wounds due to peripheral hypoxia [3, 4], lower bioavailability of nitric oxide (NO), iron overload, and an impaired endothelial function [5]. Chronic leg ulceration has also been seen in Type 2 Diabetes Mellitus (T2DM) 
and in long-term venous insufficiency where poor perfusion and altered metabolism set up a chronic inflammation that impairs repair and wound closure $[6,7]$.

Although many therapies have been explored for leg ulcers, none has been completely satisfactory. In our clinic, we obtained complete rapid closure of a longstanding indolent ulcer in the ankle of a $\beta$ thalassaemia patient with a homozygous $\beta$ globin mutation using a mixture of Platelet-Derived Wound Healing Factor (PDWHF) prepared from a pooled platelet concentrate of a matching blood group. The application of the PDWHF resulted in a remarkable change in ulcer appearance which was completely cured after 141 days of treatment. The locally applied PDWHF appears to have stimulated the granulation tissue formation and accelerated the reepithelization.

Due to their ability to differentiate into various cell types and their immunomodulatory properties [8-10] mesenchymal stem cells (MSCs) are thought to have therapeutic potential in the healing of various types of skin defects including leg ulcers, trauma, burn wounds, and scar excision [11] due to their involvement in every stage of the wound healing process [12]. The resolution of inflammation is essential to successful wound healing, and chronic inflammation can lead to poor healing outcomes. Studies have shown that MSCs possess both anti-inflammatory and pro-inflammatory properties, promoting inflammation when the immune system is under-activated and exerting immunosuppressive effects when the immune system is over-activated to avoid damage secondary to inflammation [12, 13]. MSCs stimulated by pro-inflammatory cytokines, including tumor necrosis factor (TNF) and interferon-gamma (IFN-y), modulate immunosuppression by secreting high levels of soluble factors, including indoleamine 2,3-dioxygenase (IDO), prostaglandin $E_{2}$ (PGE2), nitric oxide (NO), hepatocyte growth factor (HGF), haem oxygenase (HO), cyclooxygenase-2 (COX-2), interleukin-4 (IL-4) and interleukin-1 (IL-1) receptor antagonist preserving T-cell activation. In addition, the MSCs exhibit a pro-inflammatory phenotype by secreting proinflammatory chemokines, including metalloproteinase-1 (MIP-1), interleukin 8 (IL-8) and interleukin 8 (IL10) which enhance the T-cell response [14-16].

To study wound healing a skin substitute scaffold can be used. This is a three-dimensional organotypic culture [17] typically used for skin biology studies and testing of topically applied products. The epithelial cells and the fibroblasts of the skin equivalent secrete cytokines, chemokines, and growth factors that favour skin regeneration and provide a protective layer over the wound $[18,19]$.

Our objectives were a) to generate a novel bioactive platelet-rich plasma (PRP)-leukocytes-depleted scaffold to develop an in vitro model of the typical clinical wound of patients with poor chronic skin perfusion and low leucocytes infiltration and b) to determine whether MSCs affect cytokine expression in this wound model. An air-liquid interface model was used to reproduce a full-thickness skin consisting of a co-culture of epithelial cells and fibroblasts, seeded into a PRP-leukocytes-depleted scaffold.

The PRP leukocytes-depleted scaffold was stimulated with calcium chloride $\left(\mathrm{CaCl}_{2}\right)$ which primes and degranulates platelets, hence providing the support structure [20] and being a source of growth factors involved in haemostasis, wound healing and tissue regeneration in various injured tissues [21]. The PRP- 
leukocytes-depleted scaffold aimed to avoid the excessive cytokine expression from white blood cells that may delay or impede the wound healing process. Although the inflammatory response is fundamental for wound healing, a subset of inflammatory cells can result in delayed healing [22]. Furthermore, leukocyte-depleted PRP is more predictable, as growth factor release and fibrin scaffold integrity are conserved when exposed to inflammatory conditions [23].

TNF is a cytokine with pleiotropic effects upon cell growth, inflammation, and immune responsiveness. Whereas the local effects of TNF are usually beneficial to the host, when generated at higher concentrations within chronic inflammatory lesions, the proinflammatory effects of TNF often become deleterious and systemic [24]. Recombinant TNF (rTNF) was therefore administered to mimic an inflammatory condition.

Expression of the genes encoding IL-8 and transforming growth factor-a (TGFA) involved in the inflammatory phase [25] and the proliferative phase [26] of wound healing was analysed to evaluate how the leucocyte depleted PRP-based skin equivalent, the rTNF administration, and the MSC infusion affect the final therapeutic outcomes in an inflammatory state.

\section{Materials And Methods}

Skin tissue biopsies discarded after medical interventions were obtained to create a skin equivalent model through a co-culture of fibroblasts and epithelial cells. Pooled Buffy coats were used to isolate peripheral blood-derived MSCs.

\section{Isolation and cell culture of primary epithelial cells and fibroblasts}

The skin biopsies were washed in Dulbecco's phosphate-buffered saline (PBS) and then suspended in Dulbecco's Modified Eagle Medium (DMEM) supplemented with antibiotics ( $50 \mu \mathrm{g} / \mathrm{mL}$ gentamycin, $0.25 \mu \mathrm{g} / \mathrm{mL}$ amphotericin B, 100 units $/ \mathrm{mL}$ penicillin, and $100 \mu \mathrm{g} / \mathrm{mL}$ streptomycin) as well as the antimycotic amphotericin B (Sigma-Aldrich, Milan, Italy). This was followed by overnight digestion at $4{ }^{\circ} \mathrm{C}$ with $1 \mathrm{mg} / \mathrm{mL}$ Collagenase/Dispase (COLLDISP-RO Roche, UK). The following day, they were incubated at $37^{\circ} \mathrm{C}$ for $1 \mathrm{~h}$ with $0.25 \%$ trypsin-EDTA solution (Sigma-Aldrich) to separate the epidermis from the dermis.

The dermis and epidermis were cut into small pieces of approximately $1 \mathrm{~mm}^{2}$ each and incubated separately at $37^{\circ} \mathrm{C}$ for $2 \mathrm{~h}$ with $0.25 \%$ Trypsin-EDTA solution and mixing every $10 \mathrm{~min}$. The enzymatic action was stopped by adding complete medium supplemented with $10 \%$ fetal bovine serum (FBS). The digested tissues were centrifuged at $100 \times \mathrm{g}$ for 10 minutes at room temperature to obtain cell pellets. The epithelial cells derived from the epidermis were plated in a 6-well plate and cultured with Stemline Keratinocyte medium II supplemented with $5 \mu \mathrm{g} / \mathrm{mL}$ hydrocortisone and $10 \mathrm{ng} / \mathrm{mL}$ human recombinant keratinocyte growth factor (KGF) (Sigma-Aldrich). The dermal cells were plated in a 6-well plate and 
cultured with DMEM/F12 (1:1 mix) supplemented with $50 \mu \mathrm{g} / \mathrm{mL}$ L-ascorbic acid and $5 \mathrm{ng} / \mathrm{mL}$ human recombinant fibroblast growth factor (FGF-basic) (Sigma-Aldrich). Both complete culture media also contained 10\% FBS, $100 \mu \mathrm{g} / \mathrm{mL}$ insulin, $50 \mu \mathrm{g} / \mathrm{mL}$ gentamycin, $0.25 \mu \mathrm{g} / \mathrm{mL}$ amphotericin $\mathrm{B}, 100 \mathrm{units} / \mathrm{mL}$ penicillin, and $100 \mu \mathrm{g} / \mathrm{mL}$ streptomycin (Sigma-Aldrich). Both cell types were cultured at $37^{\circ} \mathrm{C}$ in a humidified atmosphere and $5 \% \mathrm{CO}_{2}$.

\section{Flow Cytometry analysis of primary Epithelial Cells}

Immunofluorimetric characterization of the epithelial stem cells was performed using monoclonal antibodies (moAbs) against Fluorescein Isothiocyanate (FITC) CD34 (Hematopoietic Progenitor Cell Antigen-1, Miltenyi Biotec, Surrey, UK), Phycoerythrin (PE) CD133/2 (Prominin-1, Miltenyi Biotec), PECD326 (epithelial cell adhesion molecule, clone 187 eBioscience, Waltham, USA) Alexa Fluor 488 CD29 (Integrin beta-1, clone TS2/16, Bio Legend, UK) Phycoerythrin-Cy5 (PE-Cy5) CD44 (CD 44 molecule, clone IM7, eBioscience) and Allophycocyanin (APC) CD90 (Thy-1, clone 5E10, Bio Legend) surface antigens. PE-IgG1 FITC-IgG1, PE-Cy5 and APC-IgG1 were used as corresponding isotype controls. Flow cytometry assay was done on adherent and $70 \%$ confluent epithelial cells. Cells were incubated at $37^{\circ} \mathrm{C}$ for $10 \mathrm{~min}$ with $0.05 \%$ Trypsin-EDTA and the enzymatic action was stopped by adding $10 \%$ FBS in PBS. Cells were washed with PBS, and $200 \mu \mathrm{L}$ of cell suspension was stained with $5 \mu \mathrm{L}$ of each moAb for 20 min in the dark at room temperature. The cells were analysed with the FACS Aria II (FACS Diva version 6.1.2, Becton Dickinson, USA) and raw data analysis was performed using FCS Express 7, De Novo software. Initial forward scatter (FSC) and side scatter (SSC) distribution parameters of the cell populations were applied to exclude cell debris.

\section{Isolation and culture of peripheral blood-derived MSCs}

MSCs were isolated from a buffy coat in an EDTA anti-coagulating bag using a gradient density media separation on Histopaque-1077 (Sigma-Aldrich) at $500 \mathrm{xg}$ for $25 \mathrm{~min}$ at $20^{\circ} \mathrm{C}$. Isolated mononuclear cells were subsequently washed with PBS and centrifuged at $100 \times \mathrm{g}$ for $10 \mathrm{~min}$ at room temperature. The cell suspension containing the MSCs was resuspended in $12 \mathrm{~mL}$ of fresh cell culture medium (MesenCult Proliferation Kit, Stem Cell Technologies, UK) supplemented with $50 \mu \mathrm{g} / \mathrm{mL}$ gentamycin, $0.25 \mu \mathrm{g} / \mathrm{mL}$ amphotericin B, 100 units $/ \mathrm{mL}$ penicillin, $100 \mu \mathrm{g} / \mathrm{mL}$ streptomycin (Sigma-Aldrich) and plated in a $75 \mathrm{~cm}^{2}$ flask. MSCs were cultured at $37^{\circ} \mathrm{C}$ in a humidified atmosphere and $5 \% \mathrm{CO}_{2}$. After 48 hours, the culture medium was changed to remove the non-adherent cells. The medium was changed every three to four days until confluence was reached.

\section{Flow cytometry analysis of the MSCs}

Cytofluorimetric characterization and cell sorting of MSCs was done with moAbs against the surface antigens FITC- CD105 (Endoglin, clone 43A3, Bio Legend), Alexa Fluor 488 CD29 (Integrin beta-1, clone TS2/16, Bio Legend), PE-Cy5 CD44 (CD 44 molecule, clone IM7, eBioscience), PE-Cyanine7 (PE/Cy7) CD73 (Ecto-5'-nucleotidase, clone TY/11.8, Bio Legend), PE-CD34 (clone 561, Bio Legend) and Peridinin Chlorophyll Protein Complex (PercP) CD45 (Leukocyte common antigen, clone HI30, Bio Legend). FITCIgG1, PE-Cy5-IgG1, PE-Cy7-IgG1, PE-IgG1 and PerCP-IgG1 were used as corresponding isotype controls. 
Adherent and confluent at 70\% at first passage MSCs were treated with $0.05 \%$ Trypsin-EDTA for 10 minutes at $37^{\circ} \mathrm{C}$ and the enzymatic action was stopped by adding $10 \%$ FBS in PBS. Cells were washed with PBS, and $200 \mu \mathrm{L}$ of cell suspension was stained with $5 \mu \mathrm{L}$ of each moAb for 20 min at room temperature in the dark. The cell suspension was analysed with FACS Aria II (FACS Diva version 6.1.2, Becton Dickinson), and raw data analysis was performed using FCS Express 7, De Novo software. Initial forward scatter (FSC) and side scatter (SSC) distribution parameters of the cell populations were applied to exclude cell debris.

\section{Differentiation of the MSCs into Osteocytes, Chondrocytes, and Adipocytes}

The StemPro ${ }^{\mathrm{TM}}$ Supplement kits (Gibco ${ }^{\mathrm{TM}}$, Thermo Fisher Scientific, Waltham, USA) were used to differentiate the MSCs into three lineages: osteocytes, chondrocytes, and adipocytes. The culture media were supplemented with $50 \mu \mathrm{g} / \mathrm{mL}$ gentamycin, $0.25 \mu \mathrm{g} / \mathrm{mL}$ amphotericin $\mathrm{B}, 100$ units $/ \mathrm{mL}$ penicillin, and $100 \mu \mathrm{g} / \mathrm{mL}$ streptomycin (Sigma-Aldrich). Differentiations were carried out according to the manufacturer's protocol. MSC differentiation into the three lineages was assayed using standard protocols by Von Kossa staining for osteocytes, Toluidine Blue for chondrocytes, and Oil Red 0 staining for adipocytes. Counterstaining was done with a $5 \%$ aluminum-sulphate solution for osteocytes and with Mayer's Haematoxylin Solution for adipocytes.

\section{Cell count and viability}

Cell count and viability of the three cellular components involved in the study were performed before the assembly of the experimental model and administering the MSCs to the wound model. The assay was performed with Countess TM II Automated Cell Counter using a 0.4\% Trypan Blue solution (Thermo Fisher Scientific) as per the manufacturer's protocol. The analyses were performed in triplicate.

\section{Preparation of the leukocyte-depleted PRP-based skin equivalent}

Apheresis donor platelet concentrates were transferred into $50 \mathrm{~mL}$ centrifuge tubes and centrifuged for

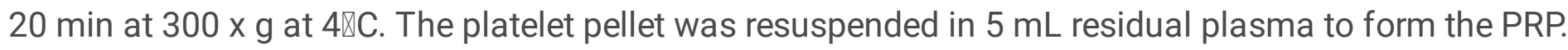
$1 \mathrm{~mL}$ of PRP was mixed with $1 \mathrm{~mL} 20 \mathrm{mM}$ calcium chloride $\left(\mathrm{CaCl}_{2}\right)$ solution and $6 \times 10^{4} \mathrm{cells} / \mathrm{cm}^{2}$ fibroblasts. The mixed solution was poured into a $24 \mathrm{~mm}$ trans-well with a $0.4 \mu \mathrm{m}$ pore polyester membrane insert and a cell growth area of $4.67 \mathrm{~cm}^{2}$ (Corning Trans-well, Sigma-Aldrich) and left at 37هC in a $\mathrm{CO}_{2}$ incubator for $24 \mathrm{~h}$. The $\mathrm{CaCl}_{2}$ worked as activator for the formation of autologous thrombin and allowed the PRP-based derma equivalent to solidify.

The epithelial cells were seeded on the PRP-based derma equivalent with a density of $6 \times 10^{4} \mathrm{cells} / \mathrm{cm}^{2}$ to establish the prototype skin equivalent. This skin model was cultured with an air-liquid interface system allowing the development of a multi-layered skin equivalent. Once fully developed, the skin equivalents were collected and fixed for $24 \mathrm{~h}$ at room temperature in $10 \%$ neutral buffered formaldehyde for 
sectioning and processing using a short histology protocol, with an overnight incubation step in $60 \%$ ethanol. The tissue-equivalent sections were embedded in wax blocks, cut at $5 \mu \mathrm{m}$, and transferred to slides and stained with Mayer's Haematoxylin-Eosin solutions (Sigma-Aldrich).

\section{The in vitro experimental model of wound healing}

In order to create an in vitro experimental model of wound healing, a scratch injury was inflicted. Administration of human rTNF (Bachem AG, Switzerland) was used to mimic an inflammatory condition. The infusion of peripheral blood-derived MSCs was done $24 \mathrm{~h}$ after the administration of the rTNF to evaluate how their immunomodulatory properties affect the final therapeutic outcomes in an inflammatory state. The three different conditions of wound healing created in the study were:

Control: a scratch injury was inflicted but no rTNF or MSC was subsequently administered.

Treated: A wound was inflicted and $30 \mathrm{ng} / \mathrm{ml}$ of $\mathrm{rTNF}$ was administered $3 \mathrm{~h}$ after wound infliction. The purpose of this condition was to reproduce an inflammatory condition.

Study: A wound was inflicted, $30 \mathrm{ng} / \mathrm{ml}$ of rTNF was administered $3 \mathrm{~h}$ after wound infliction, and $6 \times 10^{4}$ cells $/ \mathrm{cm}^{2}$ MSCs were infused $24 \mathrm{~h}$ after the administration of rTNF. The purpose of this condition was to study whether the presence of MSCs alters the inflammatory response.

Skin equivalent models from all conditions were collected at day 0 ( $3 \mathrm{~h}$ after wound infliction) and then at 1, 2, 4- and 8-day intervals after the wound was inflicted. The in vitro model was repeated in biological triplicate.

\section{RNA extraction and qPCR}

RNA was extracted from $5 \times 10 \bigotimes$ adherent MSCs, $5 \times 10 \bigotimes$ adherent fibroblasts, and the leukocyte-depleted PRP-based skin equivalents using the Pure Link® RNA Mini Kit (Thermo Fisher Scientific). In brief, leukocyte-depleted PRP-based skin equivalents were harvested quickly and were immediately digested and homogenised with $45 \mu \mathrm{l}$ of Digestion Buffer and $5 \mu$ of Proteinase K using a homogenizer (Speed Mill PLUS Analytic Jena AG, Germany). The cycles of homogenisation were: $30 \mathrm{sec}$ high speed, $1 \mathrm{~min}$ pause, $30 \mathrm{sec}$ high speed. RNA was then extracted from the homogenised tissue according to the manufacturer's protocol.

RNA quality control and measurement of the amount of total RNA were performed using a Nanodrop 2000 Instrument (Thermo Fisher Scientific). Complementary DNA (cDNA) was produced from $50 \mathrm{ng}$ of RNA from each sample using the Revert Aid ${ }^{\text {TM }}$ First Strand cDNA Synthesis Kit (Thermo Fisher Scientific). qPCR was performed using Rotor-Gene Q Series Software 2.1.0. (Qiagen, Valencia, California, USA). One microliter of the neat cDNA was amplified in a final volume of $20 \mu \mathrm{L}$ with $5 x$ HOT FIREPol Eva Green qPCR Super mix (Solis BioDyne, Tartu, Estonia) and primers for IL8, TGFA, CD34, CD45, CD90, CD73, CD105, CD44, CD29, and ACTB (Table 1). Thermal cycling proceeded for $12 \mathrm{~min}$ at $95^{\circ} \mathrm{C}$ followed by 40 cycles at $95^{\circ} \mathrm{C}$ for $15 \mathrm{~s}, 60^{\circ} \mathrm{C}$ for $30 \mathrm{~s}$, and $72^{\circ} \mathrm{C}$ for $30 \mathrm{~s}$. All real-time PCR reactions were performed in 
triplicate. The relative expressions of mRNAs were calculated using the comparative Ct method $\left(2^{\wedge}(-\Delta \Delta C t)\right.$ and normalized against the endogenous reference gene ACTB (encoding $\beta$-Actin), and the data are reported as the mRNA fold change. The expression levels of the skin equivalent models before scratching were used as calibrators.

Table 1

Primer sequences and amplicon sizes for each gene analysed in the study.

\begin{tabular}{|llll|}
\hline Gene & Forward Primer (5'-3') & Reverse Primer (5'-3') & Fragment size \\
\hline CD34 & TGAAGCCTAGCCTGTCAC & ATAAGACCTCCAGCTGTGCG & $180 \mathrm{bp}$ \\
\hline CD44 & CCAATGCCTTTGATGGACCA & GAATCAGATGGACACTCACA & $314 \mathrm{bp}$ \\
\hline CD45 & GTGTTTCATCAGTACAGACG & GCTGTCATTTCAACCACAAC & $191 \mathrm{bp}$ \\
\hline CD73 & ATGGTGTGGAAGGACTGATC & CATCGCTCAGAAAGTGAGG & $310 \mathrm{bp}$ \\
\hline CD29 & GGATTCTCTTTGGCACTGTGG & CTGCTCCTGCTCTCCCTCT & $248 \mathrm{bp}$ \\
\hline CD105 & GGGGTCAACACCACAGAG & CACATCCTGAGGGTCCTG & $261 \mathrm{bp}$ \\
\hline IL8 & GAGAGTGATTGAGAGTGGACCAC & AAACTGGGTGCAGAGGGTTGTG & $90 \mathrm{bp}$ \\
\hline TGFA & GGTCCGAAAACACTGTGAGTGG & AAGAGCCCAGAGGAGGAGTTTG & $108 \mathrm{bp}$ \\
\hline ACTB & AGTCCTAGCTACTCCGGAGGC & CGGCTATTCTCGCAGCTCAC & $113 \mathrm{bp}$ \\
\hline
\end{tabular}

\section{Statistical analysis}

The data are presented as mean \pm standard deviation (SD). The statistical significance was determined using the Wilcoxon signed-rank test, a nonparametric alternative to paired t-test, or a paired student t-test. $\mathrm{P}<0.05$ was considered statistically significant.

\section{Results}

\section{Successful isolation and culture of primary epithelial cells, fibroblasts, and skin equivalent.}

The epithelial cells displayed a short and wide spindle-shape and epithelial morphology like a "pavement stone" (Fig. 1A). The cultures reached confluence and were ready to passage within two weeks. The growth of fibroblasts from the dermal tissue was observed by day 10 after tissue plating. The dermal tissue was removed from the plate 15 days after plating, where the proliferating fibroblasts initiated the primary culture reaching confluence at day 20 after plating (Fig. 1B) 
The skin equivalent model was assembled through a co-culture of epithelial cells and fibroblasts-seeded into the PRP-leucocyte depleted scaffold and cultured in an air-liquid interface system allowing the development of a multi-layered skin equivalent (Fig. 1C).

Microscopical observation of the scaffold confirmed the presence of confluent and multi-layered epithelial cells (Fig. 1D), and the presence of proliferating spindle-shaped fibroblasts (Fig. 1E) on the PRP scaffold. Histological examination of the skin equivalent showed the presence of different epithelial cells organized in a typical skin tissue. The nuclei of the epithelial cells and the fibroblasts were stained in violet (Fig. 1F).

\section{Characterization of primary culture of epithelial cells and fibroblasts.}

The presence of epithelial stem cells and proliferating epithelial cells in the skin equivalent allows for the development of a multi-layered epithelium. In order to identify the presence of epithelial stem cells and committed epithelial progenitors on the primary epithelial cell culture we evaluated the expression of wellestablished markers such as the epithelial stem cell markers CD34 (CD34 molecule) [27] and the CD133 (Prominin-1) [28], CD90 [29] and the committed progenitor epithelial cells marker CD326 (epithelial cell adhesion molecule) [30].

Epithelial cells were also identified through the presence of specif lineage markes such as CD29 and CD44.

PE-IgG1 FITC-IgG1, PE-Cy5 and APC-IgG1 were used as negative controls to identify and quantify the percentage of positivity of the stained population for each marker. $45.67 \%$ of the cultured epithelial cells were positive for CD29 (Fig. 2A), 29.53\% were positive for CD44 (Fig. 2B), 12.72\% were positive for CD 90 (Fig. 2C), and 9.73\% were positive for CD34 (Fig. 2D), $6.62 \%$ were positive for CD326 (Fig. 2E) and $2.52 \%$ were positive for CD133 (Fig. 2F).

Gene expression analysis of the primary fibroblasts culture showed high expression of $C D 105$ (mean \pm SD: $25.4 \pm 0.07$, ) and $C D 90(28.5 \pm 0.11)$, while a lower expression of $C D 73(2.68 \pm 0.32 S D)$ was detected (Fig. 2G). Data also showed the absence of expression of the genes encoding the hemopoietic markers $C D 45(-2.62 \pm 0.40)$ and $C D 34(-3.69 \pm 0.40)$. Analysis of the products on $1.5 \%$ agarose gel confirmed the presence of the qPCR products (Fig. 2G).

\section{Characterization of peripheral blood-derived MSCs}

FITC-IgG1, PE-Cy5-IgG1, PE-Cy7-IgG1, PE-IgG1 and PerCP-IgG1 conjugated isotypes were used as negative controls to identify and quantify the percentage of positivity of the stained population for each marker. Flow cytometric analysis performed on peripheral blood-derived MSCs at the first passage showed the 
presence of two separate populations, p1 (Fig. 3A) and p2 (Fig. 4A) with different immunophenotypic patterns.

Population P1 (Fig. 3A) was found positive for CD29 (Fig. 3B), CD44 (Fig. 3C), CD73 (Fig. 3D) and CD105 (Fig. 3E). It was also found negative for the hemopoietic markers CD34 (Fig. 3F) and CD45 (Fig. 3B-F).

Population P2 (Fig. 4A) was found highly positive for CD44 (Fig. 4B) and slightly positive for CD29 (Fig. 4C), CD73 (Fig. 4D), and (CD105 Fig. 4F). It was also found negative for the hemopoietic markers CD34 (Fig. 4E) and CD45 (Fig. 4B-F).

\section{Isolation, culture and gene expression of MSCs}

Peripheral blood isolated mesenchymal stem cells showed their properties to form colonies (Fig. 5A), to adhere (Fig. 5B and Fig. 5C) and to have a spindle-shape fibroblastic picture (Fig. 5B and Fig. 5C)

The ability of the MSCs to differentiate into the three lineages was analysed by histological staining and microscopic observation. Adipocytic differentiation was reached at day 14 after stimulation, as determined by the presence of characteristic lipid vacuoles in the cytoplasm. The Oil Red 0 stained the fat in the lipid vacuoles while the nuclei were counterstained with Mayer's Haematoxylin solution. Osteogenic differentiation was achieved at day 21 after stimulation and was confirmed by the presence of dark-coloured calcium deposits stained with Von Kossa solution. Chondrogenic differentiation was noted at day 21 after stimulation as determined by the presence of proteoglycans stained with Toluidine Blue solution.

Gene expression analysis confirmed that the expression of genes for MSC-specific markers such as CD44 (mean \pm SD: $15.27 \pm 0.25)$, CD73 (14.12 \pm 1.00$)$, and CD90 (11.68 \pm 2.02$)$ was high, and low for CD105 (5.65 \pm 0.88$)$ and CD29 (4.93 \pm 1.13$)$ (Fig. 5D). Data also showed the absence of expression of the genes encoding the hemopoietic markers CD45 (-1.38 \pm 0.25$)$ and CD34 (-2.25 \pm 0.40$)$. Analysis of the qPCR products on an $1.5 \%$ agarose gel confirmed the presence of the products (Fig. 5D).

\section{Viability of the various cell types used for the wound model}

Cell viability tests were performed in triplicate on the three cellular cell types: fibroblasts, epithelial cells, and MSCs. Viability (mean \pm SD) was $85.89 \pm 0.51 \%$ for fibroblasts, $85.67 \% \pm 0.58 \%$ for epithelial cells and $85 \pm 3.2 \%$ for MSCs.

\section{Effects of scratch injury, rTNF, and MSC on gene expression in skin equivalent model}

We investigated the response of the skin equivalent cells in our experimental, leukocyte-depleted PRPbased skin equivalent model of a chronic wound associated with low skin perfusion. For this purpose, we performed real-time qPCR analysis to evaluate the level of expression of genes involved in the inflammatory (IL8) (Fig. 6A) and proliferative (TGFA) (Fig. 6B) phases at various time points in response to the scratch injury, rTNF administration, and MSC infusion. 
In these experiments, we monitored a control condition which received only the scratch and was used to verify the inflammation and proliferation of an untreated wound, while the treated condition and the study condition were administered a scratch injury and rTNF, or a scratch injury, rTNF, and MSC respectively (Fig. 6A,B).

As shown in Fig.Xx, the expression of $I L 8$ increased markedly within $3 \mathrm{~h}$ of the scratch injury, whereas the expression of TGFA decreased.

A decrease in the expression of $I L 8$ was noted in day 1 in the condition treated with $\mathrm{rTNF}(30 \mathrm{ng} / \mathrm{ml})$ when compared with the untreated control condition (Fig. 6A).

The expression of IL 8 decreased steadily in the control condition from day 2 onwards but increased slightly in the treated condition. The expression of $I L 8$ decreased significantly in the study condition in day 4 and almost reached the levels which were present prior to the injury but then increased again in day 8 (Fig. 6A).

The expression of TGFA increased in the first two days and decreased in day 4 in all groups. A significant decrease was noted in the study group between day 4 and day 8 (Fig. 6B).

\section{Discussion}

Skin equivalents represent the first examples of three-dimensional organotypic cultures which are often used for in vitro research study of normal and abnormal skin biology [17, 31].

In this study, we developed a new wound model on which to observe the immune response during the wound healing process through the expression of IL 8 and TGFA. The control condition was not treated, the treated condition was given an additional inflammatory stimulus through the administration of $30 \mathrm{ng} / \mathrm{mL}$ rTNF which regulates genes that code for inflammatory mediators [32], while the study condition was administered with $30 \mathrm{ng} / \mathrm{mL} \mathrm{rTNF}$ and $6 \times 10^{4} \mathrm{cells} / \mathrm{cm}^{2} \mathrm{MSCs}$. This model is shown in Fig. 7.

Studies on monolayer cultures of keratinocytes submerged into culture media do not resemble the true nature of the physiological process of wound healing [33]. Multi-layered differentiated models are comparable to native skin and produce excellent results when analysing epithelial attachment, proliferation, differentiation, and dermal remodelling [34]. Such models support further expertise of skin biology and skin diseases, without the complexity of the intrinsic interactions found in native skin [34, 35].

One example of a skin model cultured in an air-liquid interface system is the In Vitro Reconstructed Human Epidermis [36], which does not contain fibroblasts. On the other hand, de-epidermidised dermis and collagen framework, which includes only the fibroblasts, basement membrane, and extracellular matrix (ECM) components and which are the most commonly used dermal equivalents [34] is not

Page 11/28 
sufficient to reproduce a skin model. It was shown that the inclusion of fibroblasts enhances the production of extracellular matrix proteins, generating a more normal epidermal architecture [34]. Therefore, the interaction between epidermal and dermal components is needed for adequate wound healing. In another study, a skin equivalent was developed by implanting keratinocytes onto the upper surface of a collagen scaffold, occupied with fibroblasts and culture at the air-liquid interface [37].

It is known that platelet-rich plasma contain more than 300 biologically active molecules containing growth factors and pro-inflammatory and immune-modulating cytokines that can activate the platelets themselves, perpetuating the inflammatory cycle [27].

Moreover, the platelets trapped into the fibrin matrix release the growth factors slowly over a duration of seven days, in contrast with the use of exogenous thrombin, where almost all growth factors are discharged during the first hour [38].

Several studies reported positive results on the application of PRP in stimulating the wound healing process [39] and increasing keratinocyte migration [35]. Previous attempts to use platelet-derived products were tested in skin tissue engineering. One study described the use of platelet lysate, combined with chitosan and 107 hyaluronic acid dressing [40]. At the same time, others used platelet lysate in conjunction with a collagen/gelatin scaffold [41] or a collagen type I gel which was mixed with PRP [42]. These studies all showed promising outcomes, supporting the approach of the use of platelet-derived products in wound healing.

Our novel skin model consisted of a leukocyte-depleted, platelet-rich plasma scaffold, with embedded fibroblasts, as dermal equivalent and seeded keratinocytes on it as multi-layered epidermidis (Fig. 7). Calcium chloride was used as an activator to initiate the formation of autologous thrombin from prothrombin, forming a fibrin clot that provided a surface for keratinocyte seeding and enabled the skin cells to mature into stratum corner and basal, spinous and granular layers. The lack of leukocytes allowed for the mimicking of typical chronic wounds of patients with poor skin perfusion and low leukocyte infiltration. The leukocyte-depletion allowed for the evaluation of the immunomodulatory properties of the infused MSCs, which modulate the IL 8 and TGFA secretion.

We subsequently used our new wound model to analyse cytokine gene expression under three conditions: control, treated, and study conditions.

In physiological wound process, the ECM components, such as fibronectin, glycosaminoglycans and collagens, regulate the dynamic and interactive process of wound healing. [43] The platelets are early modulators of the healing process [44] and the blood clot formed upon platelets activation provides a provisional "scaffolding" containing fibrin molecule and plasma fibronectin. This occurs during the first 24 hours after the injury and enables formation of a temporary matrix in the wound bed. [45] Therefore, our PRP-based scaffold as dermal equivalent reassembles the physiological scaffolding formed during the hemostatic phase and required for the normal wound process. 
The initial wave of inflammatory phase is characterized by IL8 production by platelet a-granules and skin resident cells to reduce blood loss and fill the tissue gap with a blood clot rich in platelets, macrophages, leukocytes and mast cells producing/secreting cytokines and growth factors [46-49].

The inflammatory response occurs within hours of the occurrence of the damage as a localized or systemic protective response. It is activated by molecules expressed by pathogens or associated with tissue injury and are recognized by Toll-like receptors (TLRs) present on skin resident cells [50]. TLRs activation in response to injury and inflammation is responsible for the upregulation of $I L 8$ [51-53].

A significant upregulation of IL8 expression was noted three hours after the scratch injury when compared to the levels exhibited just before, thereby confirming the success of our scaffold in mimicking the wound. On the other and, the scratch injury exhibited a down regulatory effect on the expression of TGFA.

In addition to the induction of inflammation by chemokines, other molecules such as TNF promote the inflammatory response following wounding.

It has been shown that the prolonged stimulation of their TLR receptors causes downregulation of TLR2 and TLR4, most likely as a self-regulatory mechanism to prevent overactive skewing of the immune response [54]. In our model we noted a significant down regulation of IL 8 following the administration of rTNF which appears to indicate the delayed the activation of the inflammatory response. The progression of $I L 8$ in the treated group occurred in delay (i.e., at a later time point) when compared with the control group.

TLR ligation triggers the release of inflammatory mediators initiating innate immune responses mainly through the activation of macrophages, neutrophils, leucocytes, and stromal cells including MSCs, thus creating an inflammatory environment [55-56].

Neutrophils and monocytes/macrophages represent the key cells of the inflammatory phase [57] as their simultaneously release of large number of cytokines and growth factors are crucial to initiate the next phase of the healing process [58]. Neutrophils appear in the wound area a few minutes after the injury [59] and are replaced after two or three days by monocytes that undergo a transformation into macrophages [60]. Macrophages are cells of great importance for the healing process [61] as they participate in phagocytosis and are also the main source of cytokines and growth factors stimulating the proliferation of fibroblasts and collagen biosynthesis [62-63].

It was noted that a decreased influx of neutrophils in the first 4 days after the infliction of a wound has a negative impact on healing outcomes. [64]

It is well known that macrophages switch phenotypes from an M1 pro-inflammatory phenotype to an M2 pro-repair phenotype leading to the reduction of inflammatory markers and the promotion of the proliferation phase. [65]. Moreover, macrophages secrete PDGF, TGF- $\alpha$, and bFGF, which modulate the epithelialization, collagen accumulation, and angiogenesis. [66]. During the proliferative phase there is an 
increase in migration and proliferation of fibroblasts and endothelial cells as well as keratinocytes, which secrete bFGF, EGF, VEGF, bFGF, and PDGF, TGF- $\alpha$ and KGF. TGF-a mRNAs were isolated in both wound macrophages [67] epidermal keratinocytes at the wound edge. [68]. Based on its expression level, TGFA can be considered as a biomarker of the early phase of re-epithelialization. [69]

The results obtained with our model indicate that all three conditions studied were in an inflammatory state throughout the study as shown by the lower expression of TGFA when compared with IL8.

The absence of leucocytes, which promote the resolution of the inflammation by releasing numerous potent cytokines, probably led to a delay of the proliferative phase.

In experimental models, the stimulation of MSCs with the pro-inflammatory cytokine TNF upregulates expression of a subset of TLRs, thus increasing the sensitivity of MSCs to the inflammatory milieu [70]. We postulate that the MSC infusion could modulate the expression of IL 8 and that the decrease of $I L 8$ expression in the study condition at day 2 and especially at day 4 could indicate that the presence of MSCs inhibited the inflammatory response in contrast with an increase in the treated condition.

TLR4 receptor activation triggers the MSC1 population which exhibits a pro-inflammatory profile while activation of the TLR3 receptor activates the MSC anti-inflammatory phenotype MSC2 [14, 15, 71]. MSCs are known to display an anti-inflammatory phenotype in an inflammatory environment as characterized by increased mRNA expression of IL6 [72].

Our data suggest the possibility that the MSCs modulate the inflammatory response, switching from an immunosuppressive phenotype to a pro-inflammatory phenotype and regulating the IL 8 expression. Presumably, this switch in our model occurred between day 4 and day 8 , showing a substantial increase of mRNA expression in the study condition in day 8 when compared with the treated condition.

TGFA was down regulated throughout all time points in all the three conditions in our study. Interestingly, the changes in expression of TGFA had a similar pattern of to the changes in the expression of IL 8 between days 2 and 8 in the study condition. We hypothesize that the modulation of IL 8 could affect the expression level of TGFA.

Keratinocytes and fibroblasts could have both contributed equally to synthesize IL8.

We also suggest that the presence of a pro-inflammatory cytokine (TNF) stimulates MSCs to exert their immunomodulatory properties secreting directly IL 8 or/and having a paracrine effect on IL 8 and TGFA production by acting on the resident skin cells.

Further investigation is necessary to address the specific cellular source of IL 8 and TGFA production and the cellular target of the MSCs paracrine action and hence to evaluate the clinical relevance of the infusion of MSCs in a scenario of a low blood supply in the site of the wound.

\section{Conclusion}


A leukocyte-depleted, platelet-rich plasma scaffold was developed which allowed for the mimicking of typical chronic wounds of patients with poor skin perfusion and low leukocyte infiltration. The wound model indicated accurately how the resident skin cells produce IL 8 and deregulate TGFA, in response to damage in a physiological and inflammatory state. The change in the expression level of $I L 8$ confirms that an inflammatory condition was created. Notwithstanding the absence of leukocytes, MSCs modulated the IL 8 expression in response to damage in an inflammatory environment by acting directly on skin resident cells. Therefore, MSCs could have therapeutic potential for the treatment of ulcers in patients with poor skin perfusion.

\section{List Of Abbreviation}




\begin{tabular}{|c|c|}
\hline APC & Allophycocyanin \\
\hline bFGF & Basic Fibroblast Growth Factor \\
\hline $\mathrm{CaCl}_{2}$ & Calcium Chloride \\
\hline CD & Cluster of differentiation \\
\hline cDNA & Copy DNA \\
\hline cox-2 & Cyclooxygenase-2 \\
\hline Ct & Cycle threshold \\
\hline DAMP & Danger-Associated Molecular Pattern \\
\hline DMEM & Dulbecco's Modified Eagle's Medium \\
\hline ECM & Extracellular matrix \\
\hline EDTA & Ethylenediaminetetraacetic acid \\
\hline EGF & Epidermal growth factor \\
\hline FACS & Fluorescence-activated cell sorting \\
\hline FBS & Fetal Bovine Serum \\
\hline FITC & Fluorescein isothiocyanate. \\
\hline FL & Fluorescence \\
\hline FSC & Forward Scatter \\
\hline FGF- basic & Fibroblast growth factor \\
\hline HGF & Hepatocyte Growth Factor \\
\hline HO & haem oxygenase \\
\hline IDO & Indoleamine 2,3-dioxygenase \\
\hline IFN-Y & Interferon-gamma \\
\hline IL & Interleukin \\
\hline KGF & Keratinocyte growth factor \\
\hline MMP & Matrix metallopeptidases \\
\hline MoAbs & Monoclonal Antibodies \\
\hline mRNA & Messenger RNA \\
\hline MSC & Mesenchymal Stem Cells \\
\hline NO & Nitric oxide \\
\hline
\end{tabular}

Page 16/28 


\begin{tabular}{|ll|}
\hline PBS & Phosphate-buffered saline \\
\hline PDWHF & Polymerase Chain reaction \\
\hline PDGF & Platelet-Derived Wound Healing Factor \\
\hline PerCP & Platelet Derived Growth Factor \\
\hline PGE2 & Peridinin Chlorophyll Protein Complex \\
\hline PE & Prostaglandin E2 \\
\hline PE-Cy5 & Phycoerythrin \\
\hline PE/Cy7 & Phycoerythrin-Cy5 \\
\hline PRP & PE-Cyanine7 \\
\hline qPCR & Platelet Rich Plasma \\
\hline RNA & Quantitative PCR \\
\hline rTNF & Ribonucleic acid \\
\hline SSC & Recombinant TNF \\
\hline SD & Side Scatter \\
\hline T2DM & Standard Deviation \\
\hline TGF- $\boldsymbol{\beta}$ & Type 2 Diabetes Mellitus \\
\hline TGF-a & Transforming growth factor beta \\
\hline TIMPs & Transforming growth factor alpha \\
\hline TLR & Tissue inhibitor of metalloproteinases \\
\hline TNF & Toll-like receptors \\
\hline VEGF & Dissue Necrosis Factor \\
\hline$\Delta$ Ct & Delta Ct \\
\hline
\end{tabular}

\section{Declarations}

\section{Conflict of Interest}

The authors declare that they have no conflict of interest. 
The authors are grateful to Dr Kevin Schembri Cardiothoracic Specialist at Mater Dei Hospital for providing the skin tissue biopsies. The authors are grateful to Dr Alex Aquilina, Director of the National Blood Transfusion Centre for providing the pooled buffy coat bags and the apheresis-pooled, leukocytedepleted platelet products.

\section{Ethics approval and consent to participate}

This research was approved by The University of Malta Research Ethics Committee with protocol reference number 56120L7. Apheresis-pooled, leukocyte-depleted platelet products were obtained from the National Blood Transfusion Centre.

\section{Consent for publication}

Not applicable

\section{Funding}

This research was supported by a fellowship granted by the Foundation for Medical Service (FMS), Malta Enterprise, and research funds from the Faculty of Medicine and Surgery, University of Malta. Funding reference number MDSRA01-01.

\section{Author Contributions}

ES: Conceptualized the project; isolated, cultured and characterized primary cells; assembled the skin model; performed the in vitro model of wound healing; acquired and analyzed data and wrote the first draft of the manuscript. GGa: reviewed and edited the manuscript GGr: isolated and cultured the primary cells, assembled the skin model; performed the in vitro model of wound healing; SST: performed the histological staining of the skin equivalent AF: Conceptualized the project; reviewed, edited and approved the manuscript.

\section{Availability of data and materials}

All data generated or analyzed during this study are included in this published article or is available upon request.

\section{References}

1. Ruckley CV. Socioeconomic impact of chronic venous insufficiency and leg ulcers. Angiology. 1997;48:67-69.

2. Scerri CA, Abela W, Galdies R, Pizzuto M, Grech JL, Felice AE. The beta + IVS, I-NT no. 6 (T -> C) thalassaemia in heterozygotes with an associated $\mathrm{Hb}$ Valletta or $\mathrm{Hb}$ S heterozygosity in homozygotes from Malta. Br J Haematol. 1993;83:669-671. 
3. Minniti CP, Eckman J, Sebastiani P, Steinberg MH, Ballas SK. Leg ulcers in sickle cell disease. Am J Hematol. 2010;85:831-833.

4. Minniti CP, Delaney KM, Gorbach AM, Xu D, Lee CC, Malik N et al. Vasculopathy, inflammation, and blood flow in leg ulcers of patients with sickle cell anemia. Am J Hematol. 2014;89:1-6.

5. Kohgo Y, Ikuta K, Ohtake T, Torimoto Y, Kato J. Body iron metabolism and pathophysiology of iron overload. Int J Hematol. 2008;88:7-15.

6. Sen CK. Wound healing essentials: let there be oxygen. Wound Repair Regen. 2009;17:1-18.

7. Schreml S, Szeimies RM, Prantl L, Karrer S, Landthaler M, Babilas P. Oxygen in acute and chronic wound healing. Br J Dermatol. 2010;163:257-268.

8. Yagi K, Kojima M, Oyagi S, Ikeda E, Hirose M, Isoda K et al. [Application of mesenchymal stem cells to liver regenerative medicine]. Yakugaku Zasshi. 2008;128:3-9.

9. Lee SH, Jin SY, Song JS, Seo KK, Cho KH. Paracrine effects of adipose-derived stem cells on keratinocytes and dermal fibroblasts. Ann Dermatol. 2012;24:136-143.

10. Gruttadauria S, Grosso G, Pagano D, Biondi A, Echeverri GJ, Seria E et al. Marrow-derived mesenchymal stem cells restore biochemical markers of acute liver injury in experimental model. Transplant Proc. 2013;45:480-486.

11. Uccelli A, Moretta L, Pistoia V. Mesenchymal stem cells in health and disease. Nat Rev Immunol. 2008;8:726-736.

12. Hu MS, Borrelli MR, Lorenz HP, Longaker MT, Wan DC. Mesenchymal Stromal Cells and Cutaneous Wound Healing: A Comprehensive Review of the Background, Role, and Therapeutic Potential. Stem Cells Int. 2018;2018:6901983.

13. Jiang W, Xu J. Immune modulation by mesenchymal stem cells. Cell Prolif. 2020;53:e12712.

14. Bernardo ME, Fibbe WE. Mesenchymal stromal cells: sensors and switchers of inflammation. Cell Stem Cell. 2013;13:392-402.

15. Waterman RS, Tomchuck SL, Henkle SL, Betancourt AM. A new mesenchymal stem cell (MSC) paradigm: polarization into a pro-inflammatory MSC1 or an Immunosuppressive MSC2 phenotype. PLoS One. 2010;5:e10088.

16. Le Blanc K, Mougiakakos D. Multipotent mesenchymal stromal cells and the innate immune system. Nat Rev Immunol. 2012;12:383-396.

17. Bell E, Ehrlich HP, Sher S, Merrill C, Sarber R, Hull B et al. Development and use of a living skin equivalent. Plast Reconstr Surg. 1981;67:386-392.

18. El Ghalbzouri A, Ponec M. Diffusible factors released by fibroblasts support epidermal morphogenesis and deposition of basement membrane components. Wound Repair Regen. 2004;12:359-367.

19. Kubo K, Kuroyanagi Y. A study of cytokines released from fibroblasts in cultured dermal substitute. Artif Organs. 2005;29:845-849. 
20. Crovetti G, Martinelli G, Issi M, Barone M, Guizzardi M, Campanati B et al. Platelet gel for healing cutaneous chronic wounds. Transfus Apher Sci. 2004;30:145-151.

21. Pankov R, Yamada KM. Fibronectin at a glance. J Cell Sci. 2002;115:3861-3863.

22. Dovi JV, He LK, DiPietro LA. Accelerated wound closure in neutrophil-depleted mice. J Leukoc Biol. 2003;73:448-455.

23. Anitua E, Zalduendo M, Troya M, Padilla S, Orive G. Leukocyte inclusion within a platelet rich plasmaderived fibrin scaffold stimulates a more pro-inflammatory environment and alters fibrin properties. PLoS One. 2015;10:e0121713.

24. Vassalli P. The pathophysiology of tumor necrosis factors. Annu Rev Immunol. 1992;10:411-452.

25. Baggiolini M, Loetscher P, Moser B. Interleukin-8 and the chemokine family. Int J Immunopharmacol. 1995;17:103-108.

26. Ellis S, Lin EJ, Tartar D. Immunology of Wound Healing. Curr Dermatol Rep. 2018;7:350-358.

27. Sidney LE, Branch MJ, Dunphy SE, Dua HS, Hopkinson A. Concise review: evidence for CD34 as a common marker for diverse progenitors. Stem Cells. 2014;32:1380-1389.

28. Corbeil D, Fargeas CA, Jaszai J. CD133 might be a pan marker of epithelial cells with dedifferentiation capacity. Proc Natl Acad Sci U S A. 2014;111:E1451-1452.

29. Y. Nakamura,Y. Muguruma, T. Yahata, H. Miyatake, D. Sakai,§ J. Mochida,T. Hotta, K. Ando Expression of CD90 on keratinocyte stem/progenitor cells British Journal of Dermatology 2006 154, pp1062-1070

30. Klein CE, Cordon-Cardo C, Soehnchen R, Cote RJ, Oettgen HF, Eisinger M et al. Changes in cell surface glycoprotein expression during differentiation of human keratinocytes. J Invest Dermatol. 1987;89:500-506.

31. Groeber F, Holeiter M, Hampel M, Hinderer S, Schenke-Layland K. Skin tissue engineering-in vivo and in vitro applications. Adv Drug Deliv Rev. 2011;63:352-366.

32. Bazzoni F, Beutler B. The tumor necrosis factor ligand and receptor families. N Engl J Med. 1996;334:1717-1725.

33. Bacakova L, Zikmundova M, Pajorova J, Broz A, Filova E, Blanquer A et al: Nanofibrous Scaffolds for Skin Tissue Engineering and Wound Healing Based on Synthetic Polymers. In: Applications of Nanobiotechnology 2019.

34. Ojeh NO, Navsaria HA. An in vitro skin model to study the effect of mesenchymal stem cells in wound healing and epidermal regeneration. J Biomed Mater Res A. 2014;102:2785-2792.

35. van Kilsdonk JW, van den Bogaard EH, Jansen PA, Bos C, Bergers M, Schalkwijk J. An in vitro wound healing model for evaluation of dermal substitutes. Wound Repair Regen. 2013;21:890-896.

36. Creative Bioarray. In vitro Reconstructed Human Epidermis (RHE). 2020 https://www.creativebioarray.com/in-vitro-reconstructed-human-epidermis-rhe.htm

37. O'Leary R, Arrowsmith M, Wood EJ. Characterization of the living skin equivalent as a model of cutaneous re-epithelialization. Cell Biochem Funct. 2002;20:129-141. 
38. do Amaral RJFC, Zayed NMA, Pascu El, Cavanagh B, Hobbs C, Santarella F et al. Functionalising Collagen-Based Scaffolds With Platelet-Rich Plasma for Enhanced Skin Wound Healing Potential. Front Bioeng Biotechnol. 2019;7:371.

39. Chicharro-Alcantara D, Rubio-Zaragoza M, Damia-Gimenez E, Carrillo-Poveda JM, Cuervo-Serrato B, Pelaez-Gorrea P et al. Platelet Rich Plasma: New Insights for Cutaneous Wound Healing Management. J Funct Biomater. 2018;9.

40. Rossi S, Faccendini A, Bonferoni MC, Ferrari F, Sandri G, Del Fante C et al. "Sponge-like" dressings based on biopolymers for the delivery of platelet lysate to skin chronic wounds. Int J Pharm. 2013;440:207-215.

41. Ito R, Morimoto N, Pham LH, Taira T, Kawai K, Suzuki S. Efficacy of the controlled release of concentrated platelet lysate from a collagen/gelatin scaffold for dermis-like tissue regeneration. Tissue Eng Part A. 2013;19:1398-1405.

42. Houdek MT, Wyles CC, Stalboerger PG, Terzic A, Behfar A, Moran SL. Collagen and Fractionated Platelet-Rich Plasma Scaffold for Dermal Regeneration. Plast Reconstr Surg. 2016;137:1498-1506.

43. R. Raghow, "The role of extracellular matrix in postinflammatory wound healing and fibrosis," The FASEB Journal, vol. 8, no. 11, pp. 823-831, 1994

44. R. F. Diegelmann and M. C. Evans, "Wound healing: an overview of acute, fibrotic and delayed healing," Frontiers in Bioscience, vol. 9, pp. 283-289, 2004

45. R. Riessen, T. N. Wight, C. Pastore, C. Henley, and J. M. Isner, "Distribution of hyaluronan during extracellular matrix remodeling in human restenotic arteries and balloon-injured rat carotid arteries," Circulation, vol. 93, no. 6, pp. 1141-1147, 1996

46. Kobayashi Y. The role of chemokines in neutrophil biology. Front Biosci. 2008;13:2400-2407.

47. Wetzler C, Kampfer H, Stallmeyer B, Pfeilschifter J, Frank S. Large and sustained induction of chemokines during impaired wound healing in the genetically diabetic mouse: prolonged persistence of neutrophils and macrophages during the late phase of repair. J Invest Dermatol. 2000;115:245253.

48. Singer AJ, Clark RA. Cutaneous wound healing. N Engl J Med. 1999;341:738-746.

49. Martin P. Wound healing-aiming for perfect skin regeneration. Science. 1997;276:75-81.

50. Lebre MC, van der Aar AM, van Baarsen L, van Capel TM, Schuitemaker JH, Kapsenberg ML et al. Human keratinocytes express functional Toll-like receptor 3, 4, 5, and 9. J Invest Dermatol. 2007;127:331-341.

51. Martins-Green M, Petreaca M, Wang L. Chemokines and Their Receptors Are Key Players in the Orchestra That Regulates Wound Healing. Adv Wound Care (New Rochelle). 2013;2:327-347.

52. Murdoch C, Finn A. Chemokine receptors and their role in inflammation and infectious diseases. Blood. 2000;95:3032-3043.

53. Barrientos S, Stojadinovic O, Golinko MS, Brem H, Tomic-Canic M. Growth factors and cytokines in wound healing. Wound Repair Regen. 2008;16:585-601. 
54. Mo IF, Yip KH, Chan WK, Law HK, Lau YL, Chan GC. Prolonged exposure to bacterial toxins downregulated expression of toll-like receptors in mesenchymal stromal cell-derived osteoprogenitors. BMC Cell Biol. 2008;9:52.

55. Prockop DJ, Oh JY. Mesenchymal stem/stromal cells (MSCs): role as guardians of inflammation. Mol Ther. 2012;20:14-20.

56. Mantovani A, Biswas SK, Galdiero MR, Sica A, Locati M. Macrophage plasticity and polarization in tissue repair and remodelling. J Pathol. 2013;229:176-185.

57. T. J. Koh and L. A. DiPietro, "Inflammation and wound healing: the role of the macrophage," Expert Reviews in Molecular Medicine, vol. 13, article e23, 12 pages, 2011.

58. S. K. Brancato and J. E. Albina, "Wound macrophages as key regulators of repair: origin, phenotype, and function," American Journal of Pathology, vol. 178, no. 1, pp. 19-25, 2011.

59. A. Woodfin, M.-B. Voisin, and S. Nourshargh, "Recent developments and complexities in neutrophil transmigration," Current Opinion in Hematology, vol. 17, no. 1, pp. 9-17, 2010.

60. S. Guo and L. A. DiPietro, "Critical review in oral biology \& medicine: factors affecting wound healing," Journal of Dental Research, vol. 89, no. 3, pp. 219-229, 2010

61. T. Lucas, A. Waisman, R. Ranjan et al., "Differential roles of macrophages in diverse phases of skin repair," Journal of Immunology, vol. 184, no. 7, pp. 3964-3977, 2010.

62. J. M. Shah, E. Omar, D. R. Pai, and S. Sood, "Cellular events and biomarkers of wound healing," Indian Journal of Plastic Surgery, vol. 45, no. 2, pp. 220-228, 2012.

63. S. A. Eming, T. Krieg, and J. M. Davidson, "Inflammation in wound repair: molecular and cellular mechanisms," Journal of Investigative Dermatology, vol. 127, no. 3, pp. 514-525, 2007

64. H. Ebaid, "Neutrophil depletion in the early inflammatory phase delayed cutaneous wound healing in older rats: Improvements due to the use of un-denatured camel whey protein," Diagn. Pathol. 2014, 9, 46.

65. J.M. Daley, S.K. Brancato, A.A Thomay, J.S. Reichner, J.E. Albina, "The phenotype of murine wound macrophages," J. Leukoc. Biol. 2010, 87, 59-67

66. S. K. Brancato, J. E. Albina, "Wound macrophages as key regulators of repair: origin, phenotype, and function," American Journal of Pathology, vol. 178, no. 1, pp. 19-25, 2011.

67. D.A. Rappolee, D. Mark, M.J. Banda, Z. Werb, "Wound macrophages express TGF-alpha and other growth factors in vivo: analysis by mRNA phenotyping," Science 241: 708-712, 1988.

68. R.K. Cribbs, P.A. Harding, M.H. Luquette, G.E. Besner, "Endogenous production of heparin-like EGF-like growth factor during murine partial-thickness burn wound healing," J Burn Care Rehabil 23: 116-125, 2002.

69. I. Kim, J.E. Mogford, J.D. Chao, T.A. Mustoe, "Wound epithelialization deficits in the transforming growth factor-alpha knockout mouse," Wound Repair Regen 9: 386-390, 2001

70. G. Chamberlain, J. Fox, B. Ashton, J. Middleton, "Concise review: mesenchymal stem cells: their phenotype, differentiation capacity, immunological features, and potential for homing," Stem Cells. 
2007;25:2739-2749.

71. G. Raicevic, R. Rouas, M. Najar, P. Stordeur, H.I. Boufker, D. Bron et al, "Inflammation modifies the pattern and the function of Toll-like receptors expressed by human mesenchymal stromal cells," Hum Immunol. 2010;71:235-244.

72. W. Broekman, G.D. Amatngalim, Y. de Mooij-Eijk, J. Oostendorp, H. Roelofs, C. Taube et al, "TNF-alpha and IL-1 beta-activated human mesenchymal stromal cells increase airway epithelial wound healing in vitro via activation of the epidermal growth factor receptor," Respir Res. 2016;17:3.

\section{Figures}

A

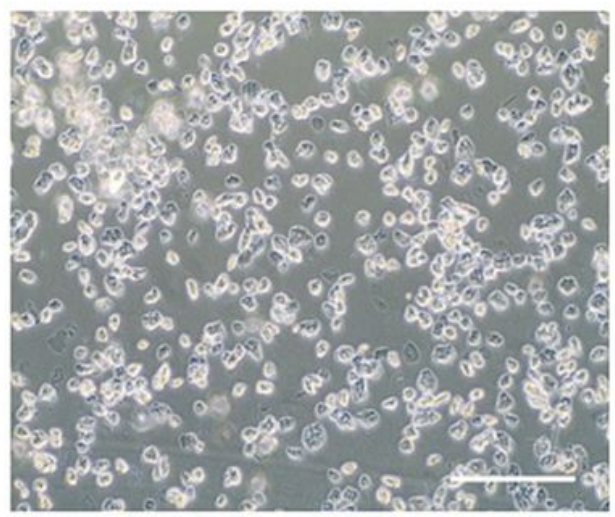

B

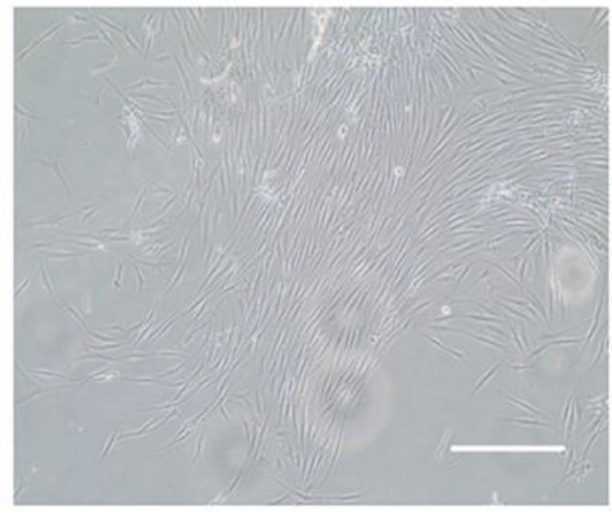

$\mathrm{E}$

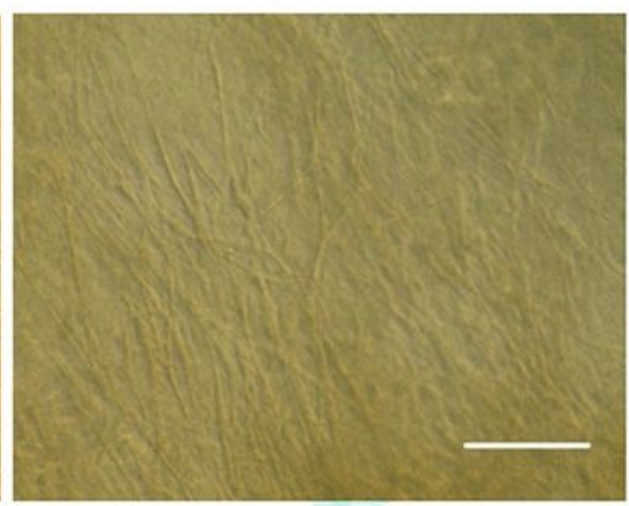

$\mathrm{C}$

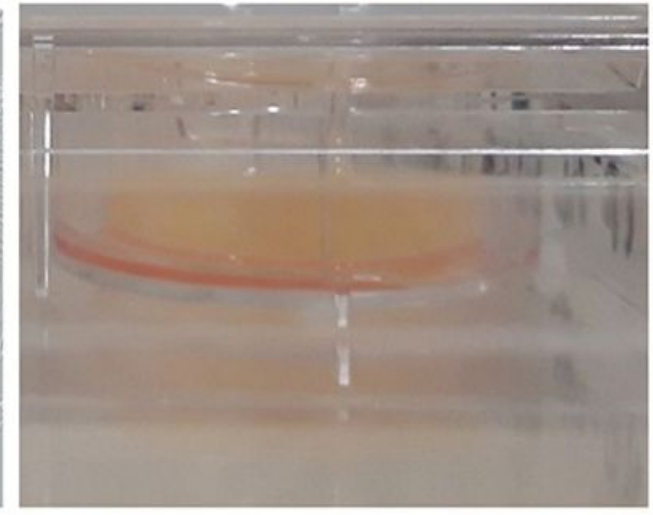

$\mathrm{F}$

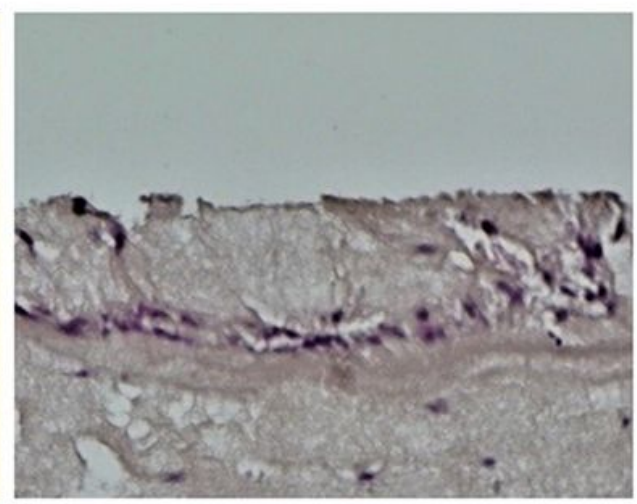

\section{Figure 1}

Morphology of the primary epithelial cells, fibroblasts, and skin equivalent A) Seeded epithelial cells showing their characteristic "pavement stone" morphology; B) Fibroblasts reaching confluence 15 days after the plating of the dermal cells; $\mathrm{C}$ ) Typical air-liquid interface system composed by a PRP-leucocyte depleted scaffold in a $24 \mathrm{~mm}$ trans-well. The skin model was assembled through a co-culture of epithelial cells and fibroblasts-seeded in the PRP-leucocyte depleted scaffold; D) Confluent epithelial cells growing in multilayers on the surface of the scaffold; E) Confluent fibroblasts embedded into the scaffold; F) Transversal section of the skin equivalent showing the presence of different epithelial cells organized into 
the different layers of the skin. Nuclei of the epithelial cells are stained in violet. The image also shows the presence of the fibroblasts (nuclei stained in violet) embedded in the PRP-leucocyte depleted scaffold stained in pink reassembling the extracellular matrix of the skin. Scale bar $=100 \mu \mathrm{m}$.
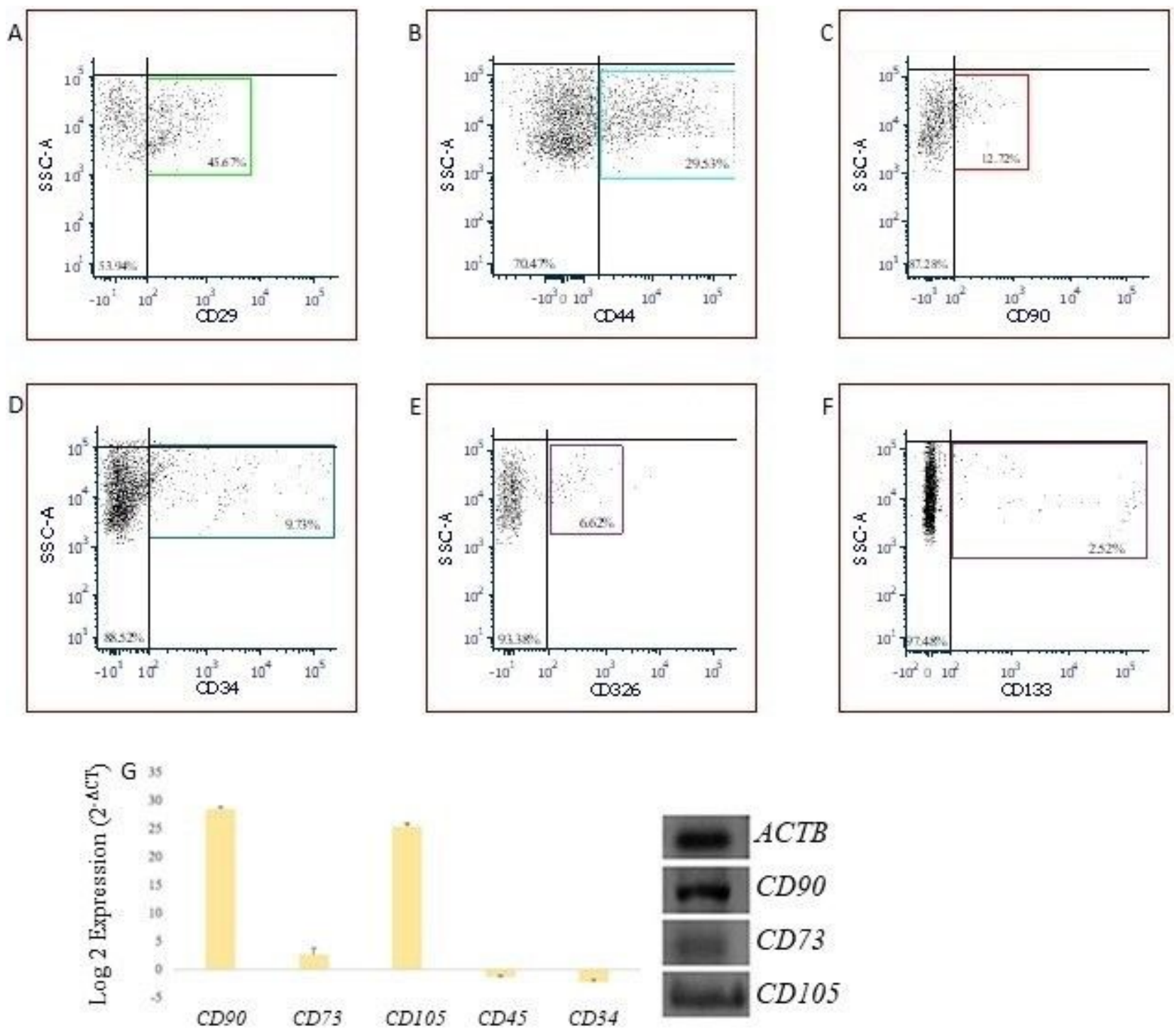

Figure 2

Flow cytometry to identify the epithelial cells, and mRNA analysis to verify the fibroblasts identity A-F) Flow cytometry scatter plots of the adherent epithelial cells side scatter (SSC)/ Fluorescence dot plots of each marker; epithelials cells were found positive for CD29 (A) and CD44 (B) lineages markers and also for CD90 (C), CD34 (D), CD326 (E), and CD133 (F) stemness markers; G) mRNA expression of genes involved in fibroblast characterization was determined by QPCR. Transcript levels were normalized to the ACTB reference gene using the 2- $\triangle \mathrm{Ct}$ method. The data are presented as mean \pm standard deviation (SD). The graph bar shows expression level of the genes CD90, CD73, CD105, CD45, and CD34 of cultured fibroblasts. Gene expression was confirmed by $1.5 \%$ agarose gels. 

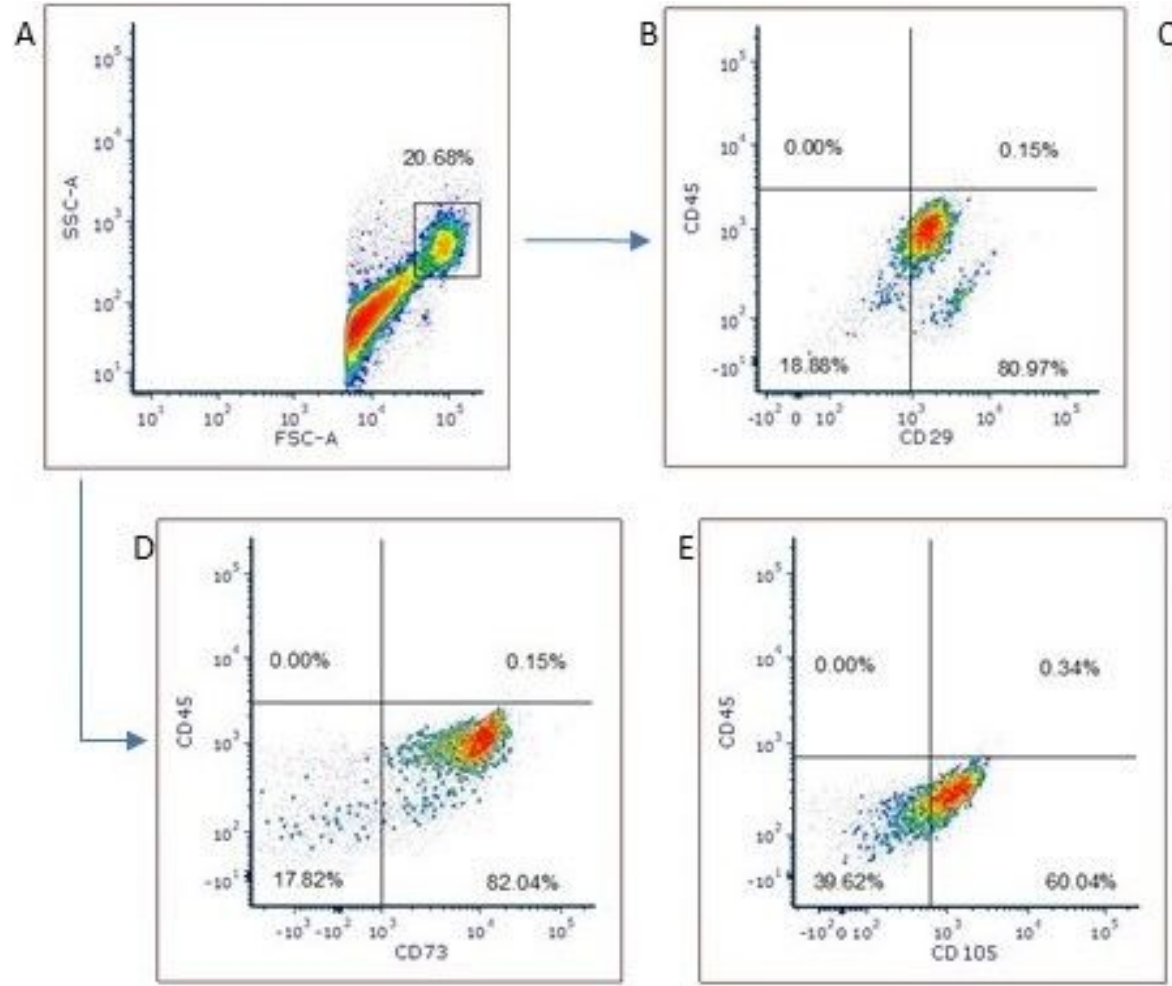
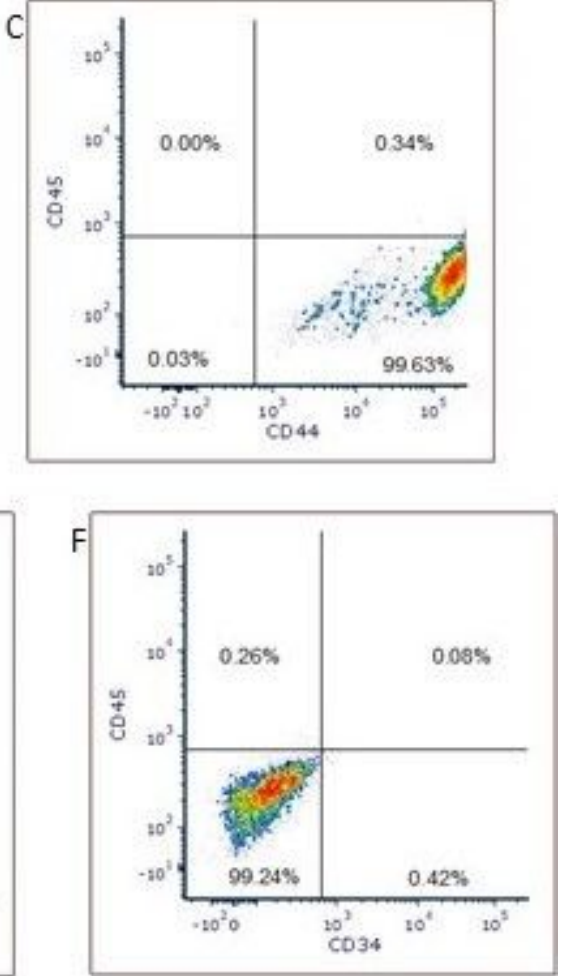

\section{Figure 3}

Flow cytometry analysis to verify the MSCs identity of Population P1 Flow cytometry to determine the positivity of MSCs. Dot plots analysis shows that population P1 (A) was positive for the specific lineage markers CD29 (B), CD44 (C), CD73 (D) and CD105 (E) and negative for the hemopoietic markers CD34 (F) and CD45 (B-F).
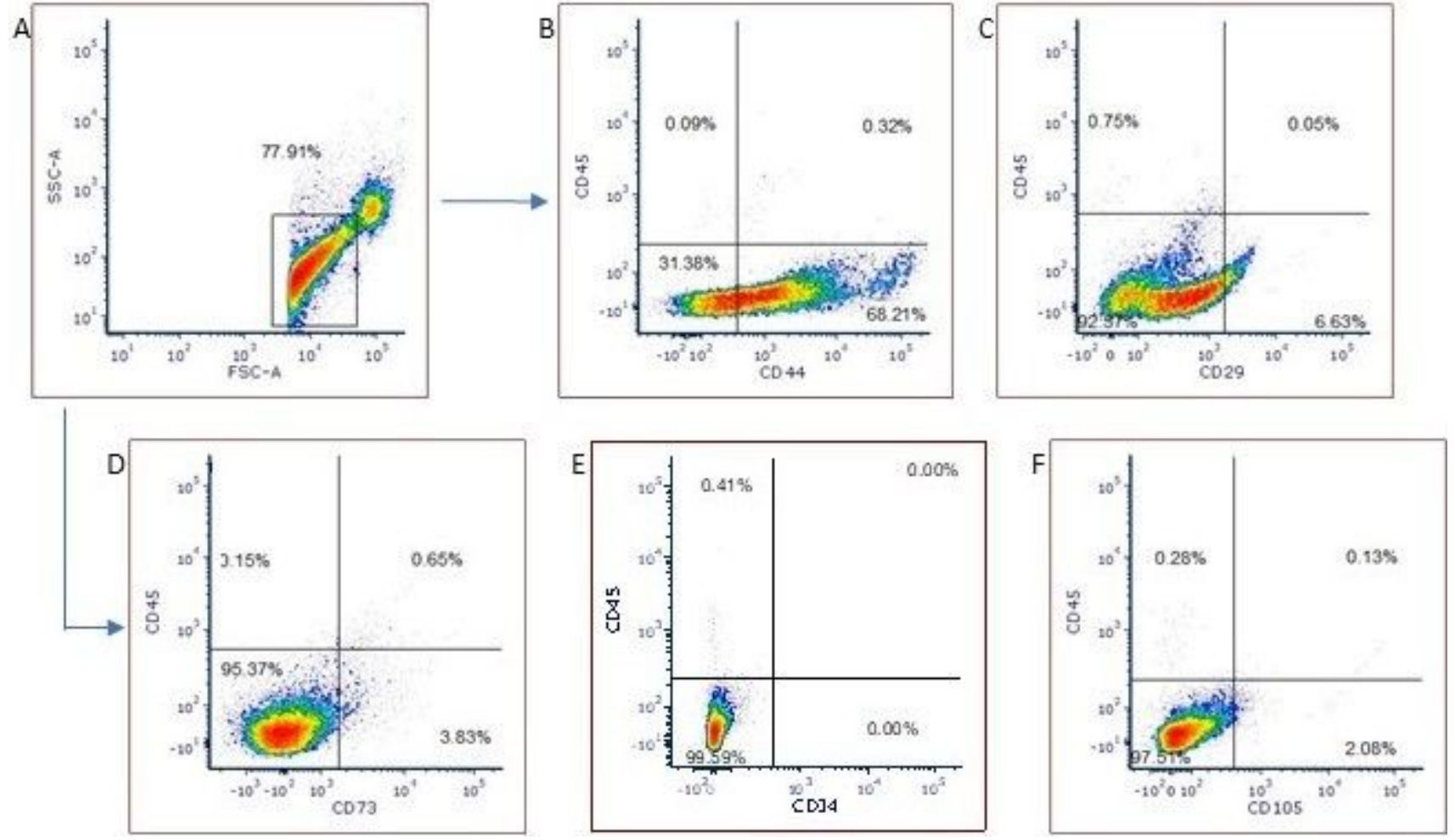

Figure 4 
Flow cytometry analysis to verify the MSCs identity of Population P2 Flow cytometry to determine the positivity of MSCs. Dot plots analysis shows that population P2 (A) was highly positive for the specific lineage marker CD44 (B) and slight positive for CD29 (C), CD73 (D) and CD105 (F). It was negative for the hemopoietic markers CD34 (E) and CD45 (B-F).

A

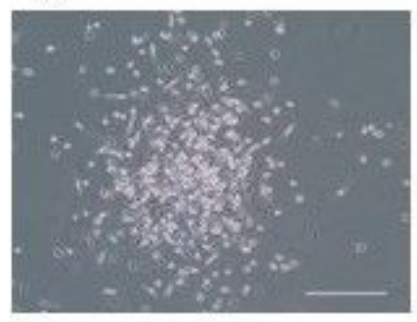

B
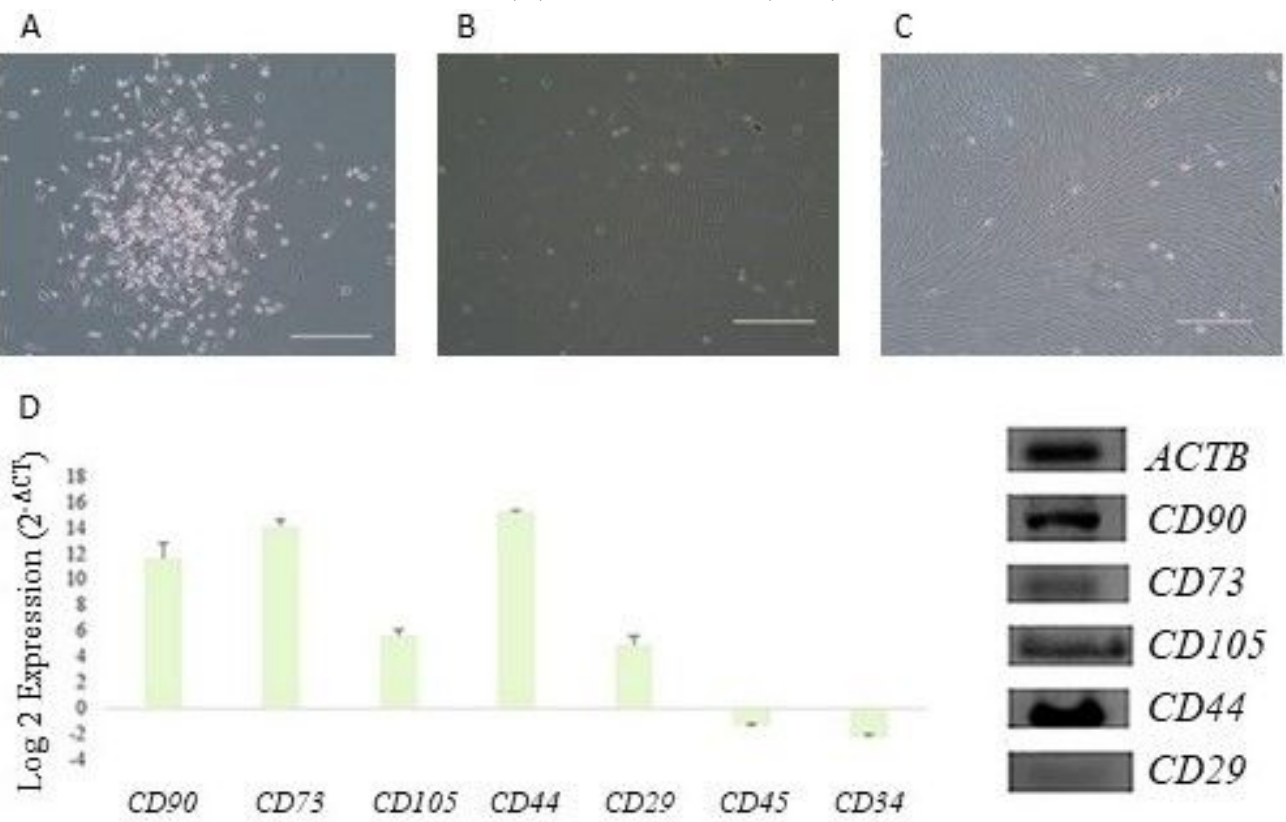

\section{Figure 5}

Isolation culture and gene expression of MSCs Isolated MSC showed their characteristics to form colonies (A), to adhere (B) and having a spindle-shape fibroblastic picture (B and $C$ ). Photos taken at day 6 of the first passage (A), at day 15 of the first passage (B) and at the second passage (C). Scale bare $100 \mu \mathrm{m}$ qPCR analysis of native MSCs mRNA expression of characteristic MSC genes was done during the second passage (D). Transcript levels were normalized to the ACTB reference gene using the 2- $\triangle \mathrm{Ct}$ method. The data are presented as mean \pm SD. The graph bar showing the mRNA expression level of CD90, CD73, CD105, CD44, CD29, CD45, and CD34 of cultured MSCs. Expression was high for CD44, CD73, CD90 and low for CD105 and CD29. Gene expression was confirmed by analysis of the products on $1.5 \%$ agarose gels. 


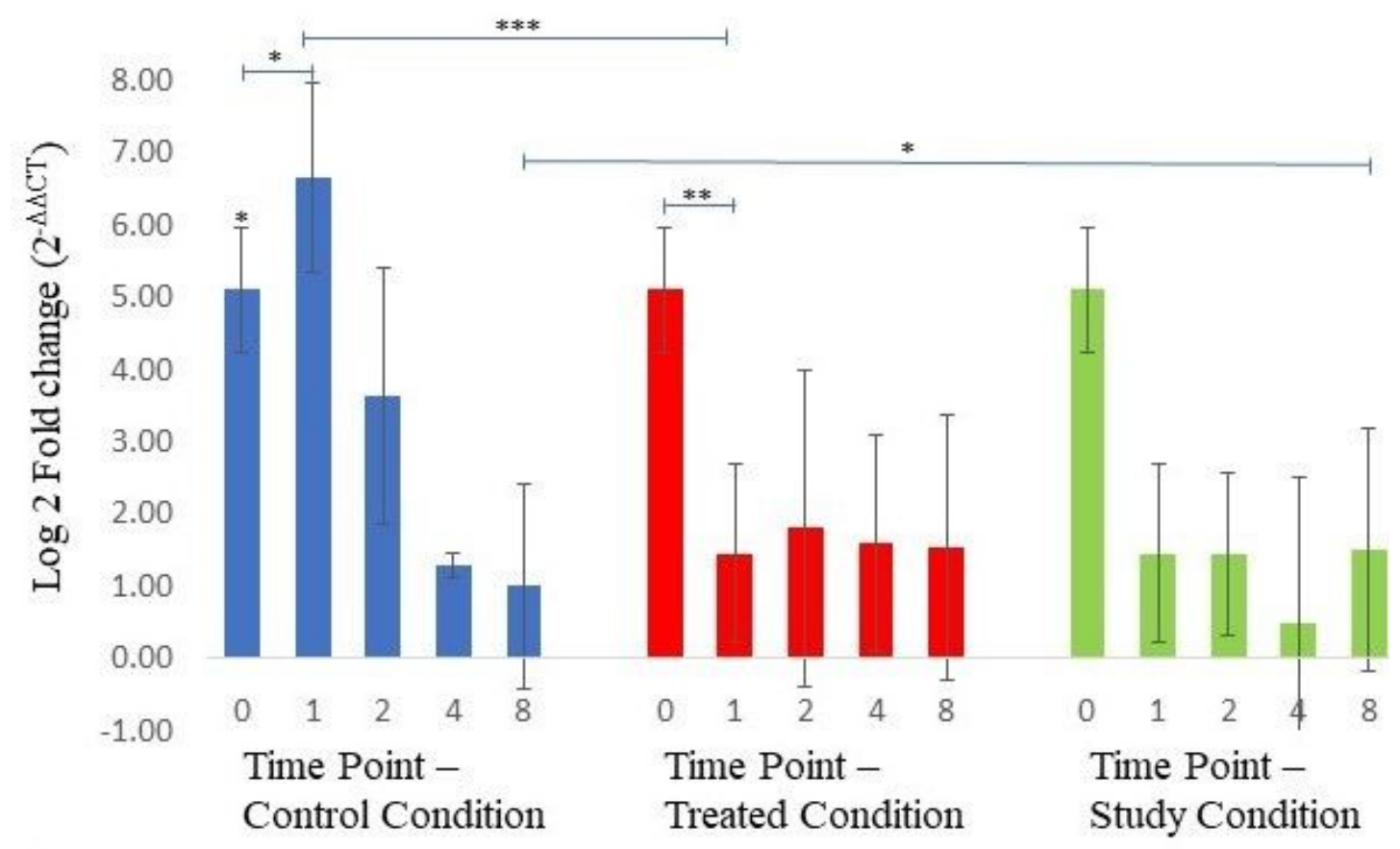

B

\section{TGFA}

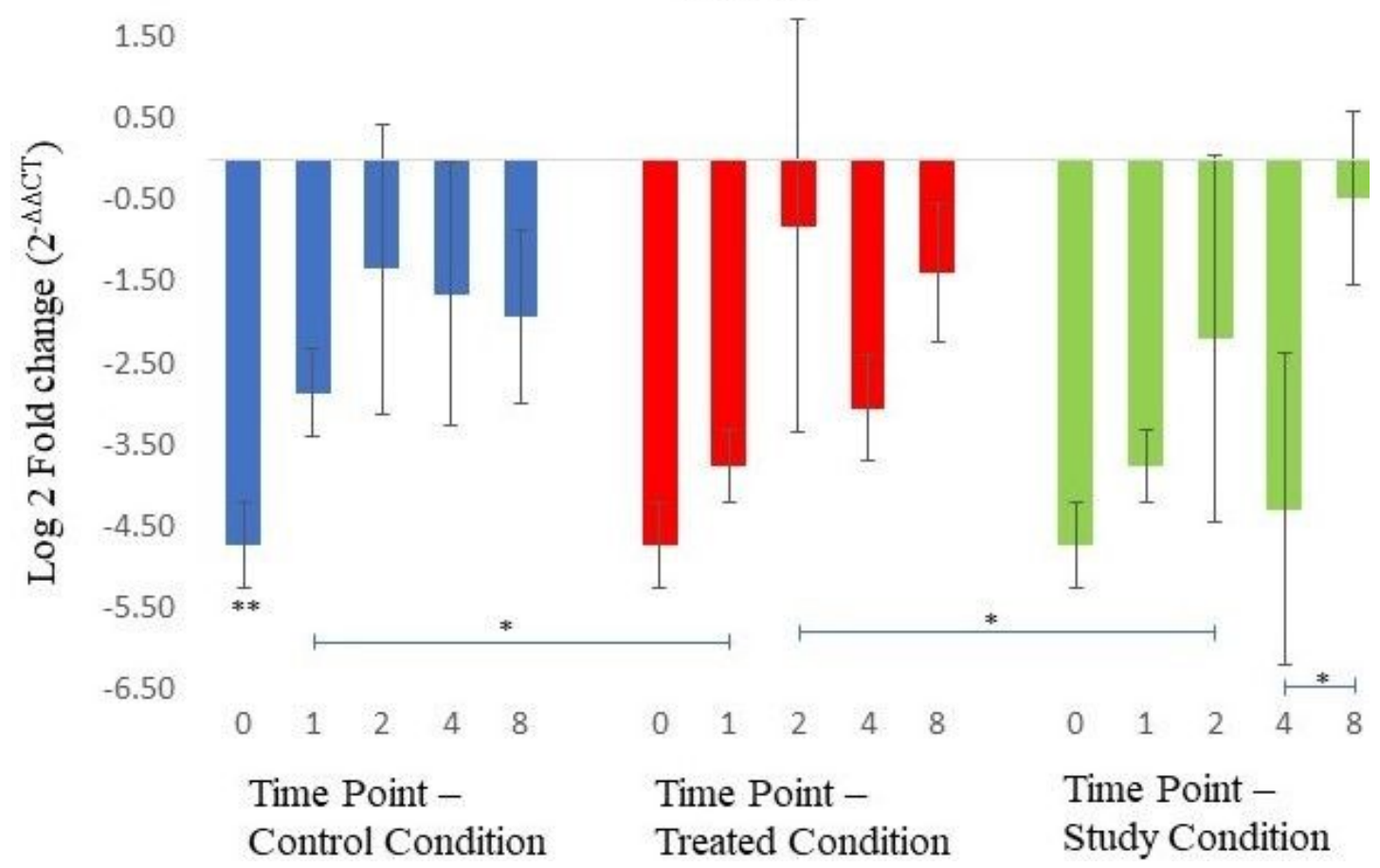

Figure 6

IL8 and TGFA Gene Expression Bar graphs showing the log fold change expression levels of the genes IL8 (A) and TGFA (B) of the control, treated, and study conditions for the five time points at which they were measured. The mRNA expression was determined by qPCR. Relative transcript levels were normalized to the ACTB reference gene. The expression levels of the skin models before scratching were used as a calibrators. Data presented as log fold change using the $2-\Delta \Delta C$ t method. $P$ values were 
worked out through a paired student t-test. $p<0.05$ was considered as statistically significant and is shown in the figure where applicable $\left({ }^{\star} p<0.05, * \star p<0.01\right.$, $\left.{ }^{\star \star *} p<0.001\right)$.

\section{IN VITRO EXPERIMENTAL MODEL OF WOUND HEALING}
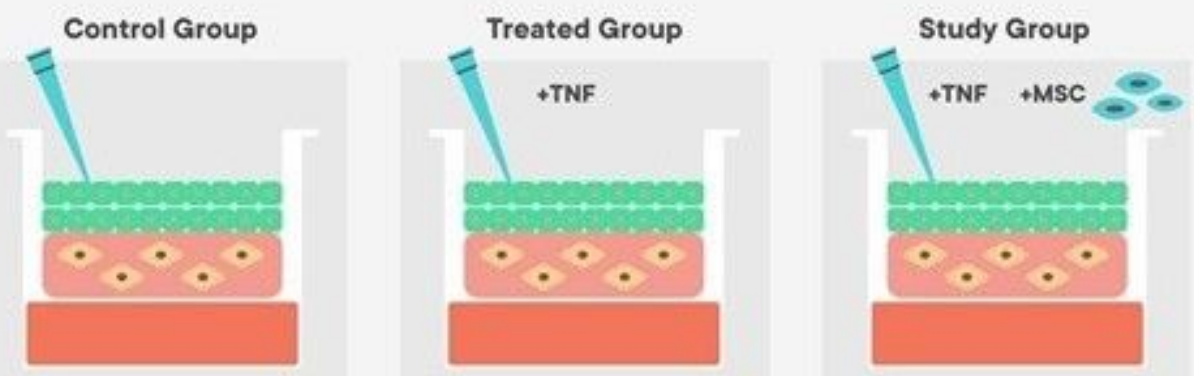

\begin{tabular}{|l|c|c|}
\hline & IL8 & TGFA \\
\hline Day0 & $\mathbf{A}$ & $\boldsymbol{\nabla}$ \\
\hline Day 1 & $\mathbf{A}$ & $\mathbf{A}$ \\
\hline Day 2 & $\boldsymbol{\nabla}$ & $\mathbf{A}$ \\
\hline Day4 & $\boldsymbol{\nabla}$ & $\boldsymbol{\nabla}$ \\
\hline Day 8 & $\boldsymbol{\nabla}$ & $\boldsymbol{\nabla}$ \\
\hline
\end{tabular}

\begin{tabular}{|l|c|c|}
\hline & IL8 & TGFA \\
\hline Day0 & $\mathbf{A}$ & $\boldsymbol{\nabla}$ \\
\hline Day 1 & $\boldsymbol{\nabla}$ & $\mathbf{A}$ \\
\hline Day 2 & $\mathbf{A}$ & $\mathbf{A}$ \\
\hline Day4 & $\boldsymbol{\nabla}$ & $\boldsymbol{\nabla}$ \\
\hline Day8 & $\boldsymbol{\nabla}$ & $\mathbf{A}$ \\
\hline
\end{tabular}

\begin{tabular}{|c|c|c|}
\hline & IL8 & TGFA \\
\hline Day 0 & $\mathbf{\Delta}$ & $\boldsymbol{\nabla}$ \\
\hline Day 1 & $\boldsymbol{\nabla}$ & $\mathbf{\Delta}$ \\
\hline Day 2 & $\mathbf{\Delta}$ & $\mathbf{\Delta}$ \\
\hline Day 4 & $\boldsymbol{\nabla}$ & $\boldsymbol{\nabla}$ \\
\hline Day 8 & $\mathbf{\Delta}$ & $\mathbf{\Delta}$ \\
\hline
\end{tabular}

LEGEND: Epithelial cels seeded onto the scattold.

C Scatlold with Nbeoblasts(orarge) embedded.

Medium.

Ait liquid interface system.

\section{Figure 7}

Experimental wound model and the changes in the expression of the genes Schematic representation of the effects of scratch assay, rTNF administration, and MSC infusion on gene expression in our skin equivalent model. IL8 and TGFA expression levels were evaluated at different time points. Down arrows in red represent downregulation while up arrows in green represent upregulation. Grey sideways arrows indicate no change in expression levels. 